\title{
Uncovering the Relation Between Environmental Damage and the Rate of Rainfall Received Through a Life Cycle Assessment (LCA) Study on Potable Water Production in Malaysia
}

\author{
Amir Hamzah Sharaai, Noor Zalina Mahmood and Abdul Halim Sulaiman \\ Additional information is available at the end of the chapter
}

http://dx.doi.org/10.5772/45851

\section{Introduction}

Global climate change is a threat that people are not aware of or do not give enough attention to. In Malaysia, many people take this problem very lightly. Global climate change is usually linked to an increase in world temperature that involves complex processes and would take a long time to take effect. However, the impact from global climate change is getting more apparent and can be felt by people of the world resulting from the increase in world temperature. The increase in world temperature, better known as global warming, is a new threat to the safety of people and nations, and could be even worse than weapons of destruction. This is due to the fact that global warming does not discriminate between skin colour and national boundaries. In Malaysia, signs of climate changes due to global warming can be seen through various disasters and symptoms affecting several areas throughout the country such as increasing sea level, haze, flood and water shortages. Climate change not only involves Malaysia, but is a global problem that must be dealt with cooperatively by every nation.

\subsection{What is global climate change?}

Global climate change, or global warming, is usually associated with the increase of world temperature. Global warming is an indication that there is an increase in surface temperature on land, in the ocean or a combination of both on a vast scale. Global warming is caused by the burning of fossil fuels such as coal, oil and gas, resulting in the increase of green house gases such as carbon dioxide, methane and chlorofluorocarbon (CFC) in the 
atmosphere. The accumulated green house gases trapped in the atmosphere causes the Earth to become warmer.

The actual causes and factors contributing to global warming are still being debated, but the fact is that evidence shows that global warming is caused by human activities and lifestyle. Development, deforestation, industries, factories and transportation are among the activities that contribute to worldwide climate change. Global climate change occurs because of the increase in green house gas in the atmosphere generated by the rapid development in production industries, timber processing, agriculture, transportation and other industries, tipping the balance against nature. Increased carbon dioxide gas in the atmosphere is generated from the burning of fossil fuel such as petrol, coal and natural gas.

According to the 4th Assessment Report (2007 Climate Change) Inter-Governmental Panel of Climate Change (IPCC), $98 \%$ of the temperature increase on Earth is caused by the release of carbon dioxide gas. Carbon dioxide concentration in the atmosphere increases from $280 \mathrm{ppm}$ recorded in the $18^{\text {th }}$ century (prior to the industrial revolution era) to $379 \mathrm{ppm}$ in 2005. In 2099, if humans maintain the current momentum of fossil fuel use as it is right now, the concentration of carbon dioxide in the atmosphere is predicted to increase to 700ppm. This situation would render the environment of the Earth no longer suitable for human habitation. Green house gas emission by Malaysia is still small compared to other countries in this world (see Table 1), nevertheless, a control system is needed to reduce the emission of green house gas into the atmosphere.

\begin{tabular}{|llc|}
\hline Country & Year & Green house emission (million tan) \\
\hline Malaysia & 1990 & 138.0 \\
& 1994 & 144.0 \\
\hline Thailand & 1990 & 225.0 \\
\hline Australia & 1990 & 572.0 \\
\hline Japan & 1990 & 1215.9 \\
& 1994 & 1276.1 \\
\hline USA & 1990 & 5895.9 \\
& 1994 & 6130.0 \\
\hline
\end{tabular}

Table 1. Green house emission by country (Minister of Science, 2000)

\subsection{The impact of world climate change on the country}

Climate change is believed to have sped up the weather process causing sudden changes within a period of time. It is threatening the safety of both the population and the nation, from the physical and psychological aspects. If not managed properly, the combination of both would create a crisis in peoples' lives, public safety/order, political stability and economic integrity. The physical effects of climate change to the country are as follows: 


\subsubsection{Natural disaster}

A change of monsoon wind direction, rising sea level and irregular rainfall are among the results of climate change. Increasing temperature of Earth will create a huge threat to human life resulting in an increased frequency of natural disasters over time. Typhoons, floods, drought and plagues of diseases related to the environment are among the natural disasters that would follow the unpredictable climate change. With $9 \%$ of land area in Malaysia (29,000 sq. km) exposed to flooding, 2.7 million people in this country might be the victims. The ever-changing weather would cause the country to face the possibility of a natural disaster. As an example, in 2006 and 2007, the state of Johor experienced flooding, resulting in 109, 831 victims to be evacuated (Bakar et al., 2007). Other states experiencing a similar situation at that time were Melaka, Pahang, Kelantan and Negeri Sembilan. A total of 344 flood evacuation centres were set up. It was reported that 17 lives were lost in this extreme flooding disaster (BBC News, 2007) linked to Hurricane Utor (The Star, 2006). In October 2008, a flash flood happened in the northern peninsular states of Kedah and Perak due to the hotter sea surface in the region (Bernama, 2008).

\subsubsection{Water source}

Rapid development in the urbanization process and industries increases the demand for water especially in the industrial and agricultural sectors, and also for domestic use. Climate change could cause Malaysia to experience increased or decreased rainfall. Increased rainfall would mean that Malaysia would be exposed to flooding, causing destruction to the infrastructure and property, and loss of life. Meanwhile, a decrease in rainfall would cause a reduction in clean water sources for domestic use, and the agricultural and industrial sectors.

During the 1977 - 78 period, drought devastated paddy production in most of the irrigation schemes in northwest peninsular of Malaysia. In 1982 and 1991, drought was responsible for the critical drop of water levels in the state of Kedah, resulting in cancellation of the offseason crop production. In 1991, the state of Melaka faced critical water problems with water levels falling below critical levels, thereby forcing severe water rationing for months in the state (Climate Ark, 2002). In 1998, the El Nino related drought caused severe water stress in the states of Kedah, Penang and Selangor. The state of Selangor was forced to impose severe water rationing in Kuala Lumpur and Petaling Jaya for many months (Angela, 2002). According to the Seventh Malaysia Plan reports, several countries experienced water shortages after 2000, including Kedah, Pulau Pinang and Selangor (Rahman, 2007).

\subsection{World climate change and the need for sustainable development}

Development can increase the quality of human life. This can be gauged by the increasing quality of products, services, health, society and culture. Development is endless and will keep expanding to fulfil the changing human vision and mission, but the development 
process usually has negative effects on the environment, thus demanding a more environmentally sound plan. Unplanned and unsustainable development has placed great pressure in every dimension of the environment (air, water, soil, health, etc.) that ultimately causes problems that not only involve local issues, but also global such as global warming. Sustainable development is the need of the hour; it can only be achieved through effective environmental management (Khan et al., 2002). Effective environmental management can be achieved through the various environmental assessment tools including life cycle assessment (LCA).

\section{Methodology of Life Cycle Assessment (LCA)}

There are four main phases in LCA as suggested in ISO 14040 series:

2.1. Goal and scope definition (ISO 14040)

2.2. Life cycle inventory (LCI) (ISO 14041)

2.3. Life cycle impact assessment (LCIA) (ISO 14042)

2.4. Life cycle assessment and interpretation (LCAI) (ISO 14043)

\subsection{Goal and scope definition}

In goal definition and scoping, the use of the results is identified, the scope of the study is stated, the functional unit is defined and a strategy and the procedures for data collection and the data quality assurance are established.

\subsubsection{Objectives}

The objective of this research is to get a clear picture of the impact potential produced from potable water production when two phases are involved, namely, production stage and construction stage using an LCIA method (in this case the Ecopoints method). This research will identify which impact is greater by comparing them using normalization and weighting procedures so that suggestions to reduce the impact can be recommended.

\subsubsection{Functional unit}

Functional unit is quantified performance of a product system as a reference unit in a life cycle assessment study (ISO14000, 2000). A constant value must be created to make the comparison (Miettinen \& Hamalainen, 1997). Functional unit for this study is the production of $1 \mathrm{~m}^{3}$ of treated water a day that fits the standard quality set by the Ministry of Health, Malaysia.

\subsubsection{Description of the system under study}

There are two stages which Became the basis of comparison in this study, namely, the production and construction stages. 


\subsubsection{Production stage}

Raw water extracted from rivers will go through the following processes in the water treatment plant (Sastry, 1996):

- Screening. Removing large, floating rubbish on the surface of the water.

- Coagulation and flocculation. The coagulation process is the process of forming particles called floc. A coagulant needs to be added to form floc. The coagulants that are normally used include aluminium sulphate, ferric sulphate and ferric chloride. Tiny flocs will in turn attract each other while at the same time pulling the dissolved organic material and particulate to combine, forming a big flocculant particle. This process is called flocculation.

- Settling. Aggregated flocs settle on the base of the settler. The accumulation of floc settlement is called settling sludge.

- Filtration. Part of the suspended matter that does not settle goes through filtration. The water passes through a filtration system consisting of sand layers and activated carbon or anthracite coal.

- Disinfection. This process is needed to eliminate the pathogen organisms that remain after filtration. Among the chemicals used for disinfection are chlorine, chloramines, chlorine dioxide, ozone and UV radiation.

\subsubsection{Construction stage}

The main building Materials used when building water treatment plants are concrete and steel. Concrete is a type of composite material which is usually used in construction. It is a combination of the following:
a. Cement
b. Fine aggregate/sand
c. Coarse aggregate
d. Water

The quality of the concrete which is produced depends on the quality of the raw materials that are being used such as cement, coarse aggregate and water, rate of mixing, the method of mixing, transportation and compression methods. If the raw materials used are not good quality, the concrete produced will be low quality and this causes the concrete to be weak and unable to fulfil the fixed specifications. So, concrete technology warrants that all the materials used should first be tested and certified through fixed standardizations before being used in construction work.

Steel increases the tensile strength of the concrete structure. Reinforcement steel functions to increase the tensility strength of the concrete structure. Types of reinforcement steel that are used are as follows:

i. Mild steel reinforcement / mild steel

ii. Reinforcement steel with high tensility

iii. Fabric steel (fabric) 
The steels that are provided are $12 \mathrm{~m}$ long, with diameters of $6 \mathrm{~mm}, 8 \mathrm{~mm}, 10 \mathrm{~mm}, 12 \mathrm{~mm}$, $16 \mathrm{~mm}, 20 \mathrm{~mm}, 22 \mathrm{~mm}, 25 \mathrm{~mm}$ and $32 \mathrm{~mm}$. The reinforcement steel will be cut and moulded according to the concrete structure design. Reinforcement steel with high tensility is used as the backbone of the concrete structure because of its high strength. Mild steel reinforcement is usually used as reinforcement fixation where high tensility is not needed. Fabric steel (fabric) is used in a wide concrete surface area such as floors and comes in sizes of $2.4 \mathrm{~m} \mathrm{x}$ $1.8 \mathrm{~m}$ with steel diameter $4 \mathrm{~mm}$ to $12 \mathrm{~mm}$. The distance between each steel rod is different based on the types of fabric. Reinforcement steel that is used should be free from any dirt and rust, so it has to be protected from water and humidity.

\subsection{Life Cycle Inventory (LCI)}

The inventory of the studied LCA system includes information on the input and output (environmental exchanges) for all the processes within the boundaries of the product system (see Figure 1). The inventory is a long list of material and energy requirements, products and co-products, as well as wastes. This list is referred to as a material and energy balance, the inventory table, or the eco-balance of the product (Guinée, 2002). This LCA study is a streamlined LCA with background data for electricity, chemicals and transport using a database contained in the Jemaipro and Simapro 7 software. Foreground data collected from the treatment plant are: (see Table 2)

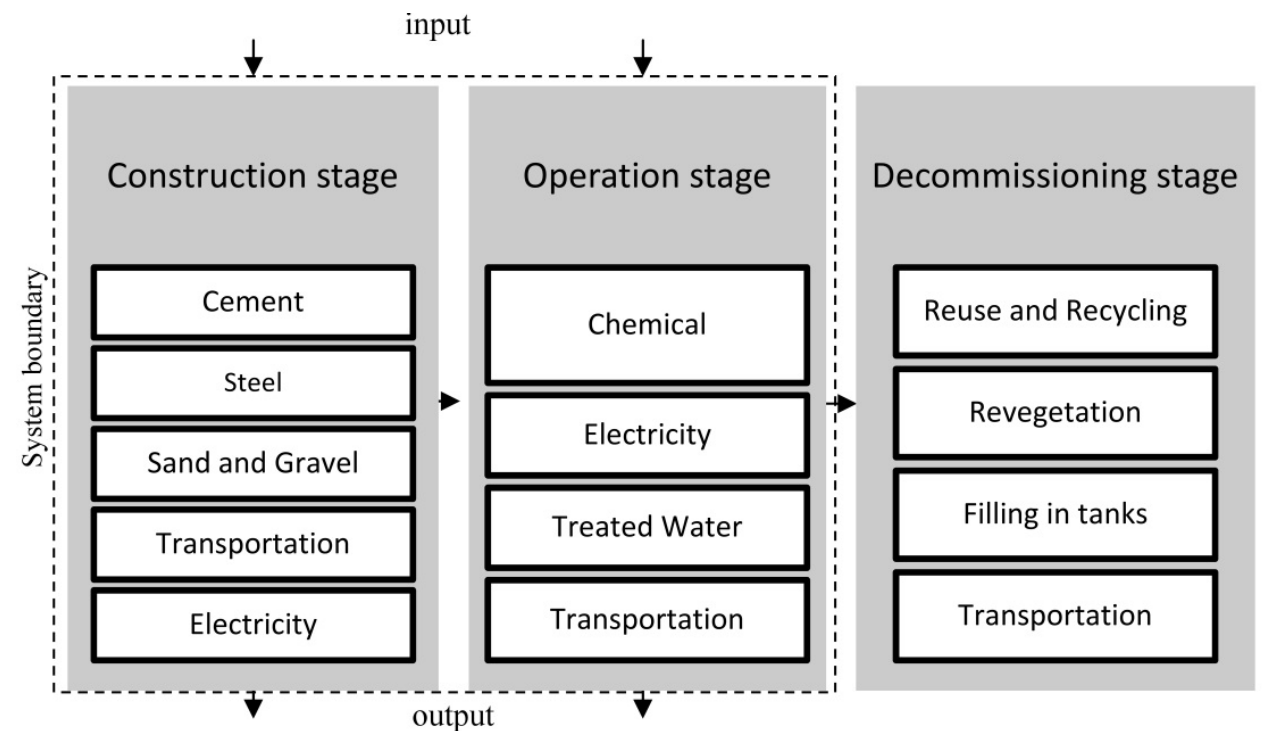

Figure 1. System Boundary of Potable Water Treatment Plant

- Electricity usage, and

- Chemicals for water treatment such as aluminium sulphate (alum), polyaluminium chloride (PAC), chlorine and calcium hydroxide (lime)

- Building materials such as steel, gravel, sand and cement 
Filtration material (activated carbon and anthracite) and coagulant (ferrochloride) are not included in this study because no water treatment plants in Malaysia use these materials.

Background data for all building materials and chemicals is obtained from Japan Environmental Management Association for Industry (JEMAI) - PAC, BUWAL 250 chlorine, alum and electricity, ETH-ESU 98 - lime, LCA Food DK - tap water, and IDEMAT 2001 - cement, steel, sand and gravel.

\begin{tabular}{|ll|ll|}
\hline Construction Stage & & Production Stage \\
\hline Steel $(\mathrm{kg})$ & 8.78 & Alum $(\mathrm{kg})$ & 22.55 \\
Cement $(\mathrm{kg})$ & 30.72 & Chlorine $(\mathrm{kg})$ & 3.65 \\
Gravel $(\mathrm{kg})$ & 70.72 & PAC $(\mathrm{kg})$ & 16.85 \\
Sand $(\mathrm{kg})$ & 47.15 & Lime $(\mathrm{kg})$ & 11.12 \\
Electricity $(\mathrm{kwh})$ & 0.09 & Electricity $(\mathrm{kwh})$ & 397.28 \\
Tap water $(\mathrm{litre})$ & 477.26 & & \\
\hline
\end{tabular}

Table 2. Foreground data for construction stage and production stage.

\subsection{Life Cycle Impact Assessment (LCIA)}

The impact assessment is used to identify the significant potential environmental effect by using the results of life cycle impact analysis (LCI). LCIA is very different from other techniques, such as environment impact assessment (EIA) and risk assessment, because the approach uses functional units. LCIA comprises four elements, namely, the classification, characterization, normalization and weighting, but normalization and weighting are optional elements (Koroneos, Dompros, Roumbas \& Moussiopoulos, 2005). According to Jolliet, Brent et al., (2003), the classification of LCI due to the impact categories is through the impact pathway which begins from LCI results until the end-point. The explanation on impact pathway is also touched upon in ISO (Jolliet, Brent et al., 2003) where:

'LCI results are classified into the impact categories and category indicators that can be stated in any LCI results (mid) with the end-point category.'

In accordance with the above explanation, two approaches have been developed to explain the inter-connection of the LCI results with the environmental impacts via mid-point or endpoint approaches (Heijungs et al., 2003; Jolliet, Margni et al., 2003; Jolliet et al., 2004; Ortiz, Francesc \& Sonnemann, 2009; Sleeswijk, van Oersc, Guinée, Struijsd \& Huijbregtsb, 2008; Soares, Toffoletto \& Deschenes, 2006). According to Bare et al. (2000), the main difference between both models is the methodology used and how category indicators are presented to translate the achieved impact categories.

Figure 2 illustrates that the impact pathway begins from LCI results until the end-point. The emission of ozone depletion gases is used as an example for the characterization of ozone depletion gases that can be conducted either until mid-point or end-point. Impact at mid- 
point is the ozone layer depletion and impact in the end-point is the protected area involving human health, natural biotic environment and manmade environment.

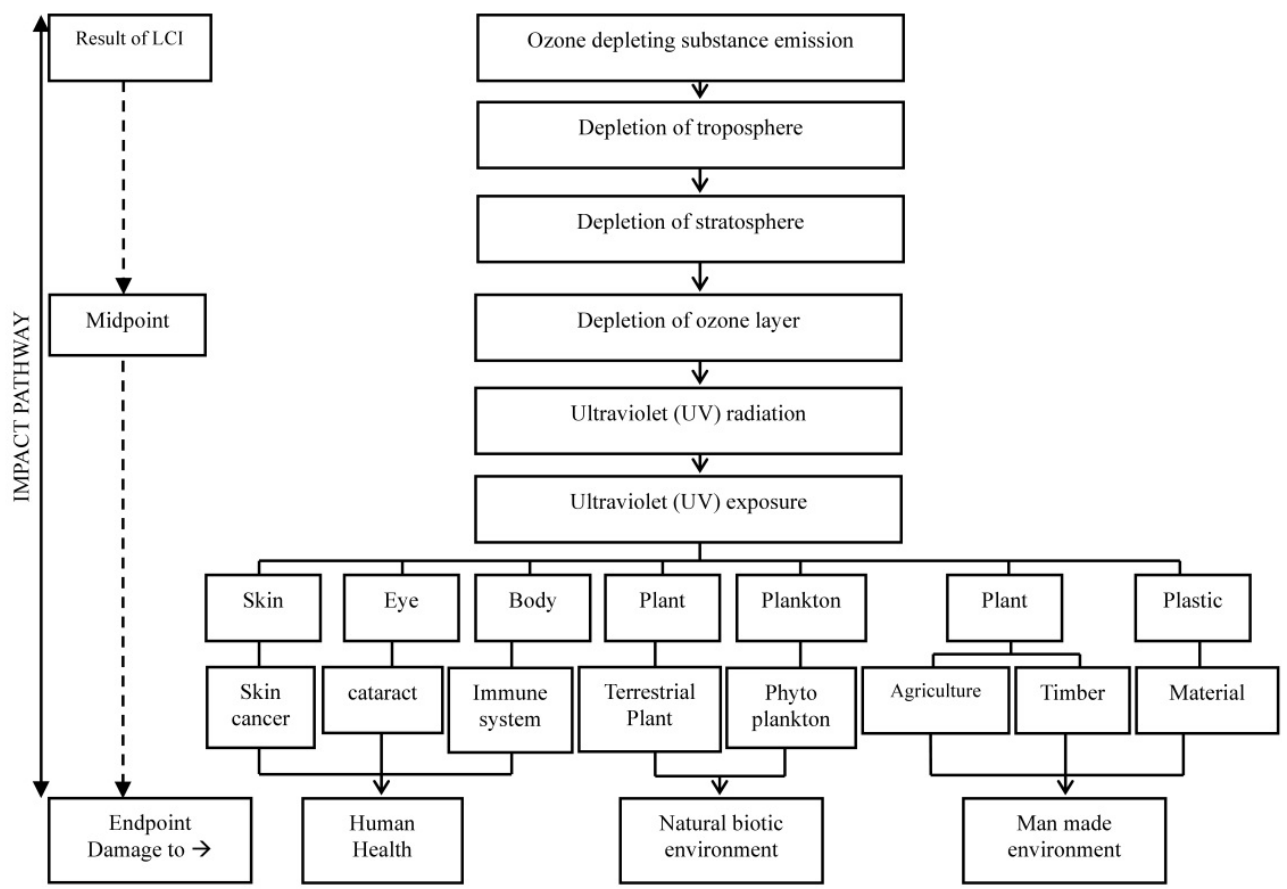

Figure 2. Impact pathway connecting the emission to several deterioration categories.

\subsubsection{Mid-point approach}

The LCIA mid-point approach is also known as the problem-oriented approach (Dreyer, Niemann \& Hauschild, 2003; Ortiz et al., 2009) or the classical impact assessment method (Jolliet, Brent et al., 2003; Jolliet et al., 2004). The term mid-point refers to the category indicator for each impact category which is expressed in the mid pathway of impact between LCI results and end-point (Josa, Aguado, Cardim \& Byars, 2007). Mid-point translates the category impact into real phenomenon such as climate change, acidification and aquatic toxicity (Sleeswijk et al., 2008). An example of the methodology that was developed using the mid-point approach is CML 2001 (Dreyer et al., 2003; Heijungs et al., 2003), EDIP 97 and TRACI (Jolliet et al., 2004).

\subsubsection{End-point approach}

The end-point LCIA methodology is also known as the damage-oriented approach (Dreyer et al., 2003). According to Heijungs et al., (2003) this approach looks at the elements inside the impact pathway that consist of independent values for society. The term 'end-point' 
refers to the category indicator for each impact category located at the end of the impact pathway as in Figure 2. End-point indicator translates the category impact based on the area of protection such as human health, natural environmental quality, natural resources and the manmade environment (Bare \& Gloria, 2008). Examples of end-point methodology are Eco-indicator 95 and 99, EPS 92, 96 and 2000, and LIME 2003 (Pennington et al., 2004). According to Reap et al. (2008), there are several factors affecting the level of confidence and suitability of LCA research result which include the options of LCIA methodology either using the mid-point or end-point approach. Reap et al. (2008) state that the end-point impact category is less comprehensive and possesses higher levels of uncertainty compared to the mid-point impact category. Nevertheless, the mid-point impact category is difficult to interpret, especially in the process of decision making because the mid-point impact category is not directly correlated with the area of protection (i.e., damage to human health, ecosystem quality and resource depletion) which is practiced by the end-point.

\subsubsection{Eco-Indicator 99 evaluation method}

LCIA for this study uses the Eco-Indicator 99 method (Eco-indicator 99 is an end-point method as mentioned in previous sub-topic) where 11 impacts classified into three damage assessment areas (refer Table 3) as listed below:

\begin{tabular}{|c|c|c|}
\hline Damage Assessment & Unit & Impact \\
\hline Human Health & DALY & $\begin{array}{l}\text { Carcinogen, radiation, } \\
\text { respiratory organic and } \\
\text { inorganic }\end{array}$ \\
\hline Ecosystem Quality & $\begin{array}{l}\mathrm{PDF}^{*} \mathrm{~m}^{2} \mathrm{yr} \\
\mathrm{PAF}^{*} \mathrm{~m}^{2} \mathrm{yr}\end{array}$ & $\begin{array}{l}\text { Climate change, ozone layer } \\
\text { and acidification } \\
\text { Ecotoxicity }\end{array}$ \\
\hline Resources & MJ surplus & $\begin{array}{l}\text { Land use, minerals and } \\
\text { fossil fuels }\end{array}$ \\
\hline
\end{tabular}

DALY: Disability Adjusted Life Years (years of disabled living or years of life lost due to the impacts) PAF: Potentially Affected Fraction (animals affected by the impacts) PDF: Potentially Disappeared Fraction (plant specie disappeared as result of the impacts) MJ: Surplus Energy (MJ) (extra energy that future generations must use to excavate scarce resources)

Table 3. Damage Assessment and Impact According to Eco-Indicator 99.

\subsubsection{Steps in Life Cycle Impact Assessment (LCIA)}

Generally there are three steps in LCIA:

2.3.4.1. Classification and characterization

2.3.4.2. Normalization, and

2.3.4.3. Weighting 


\subsubsection{Classification and characterization}

Classification is the step in which the data from the inventory analysis (the substance emissions) are grouped together into a number of impact categories (Bovea and Gallardo, 2003). Grouping to the impact categories is done according to their ability to contribute to different environmental problems. While characterization is the effect of each item on each impact category. A typical way is to use equivalency factors, in some instances also called potentials is, for example, global warming potential for a substance indicates its two relative potentials to increase the global warming effect compared to $\mathrm{CO} 2$, whose GWP is set to one. In ISO 14040 series classification and characterization are two basic mandatory elements. Below are the results of the analysis done in this study (see Figure 3).

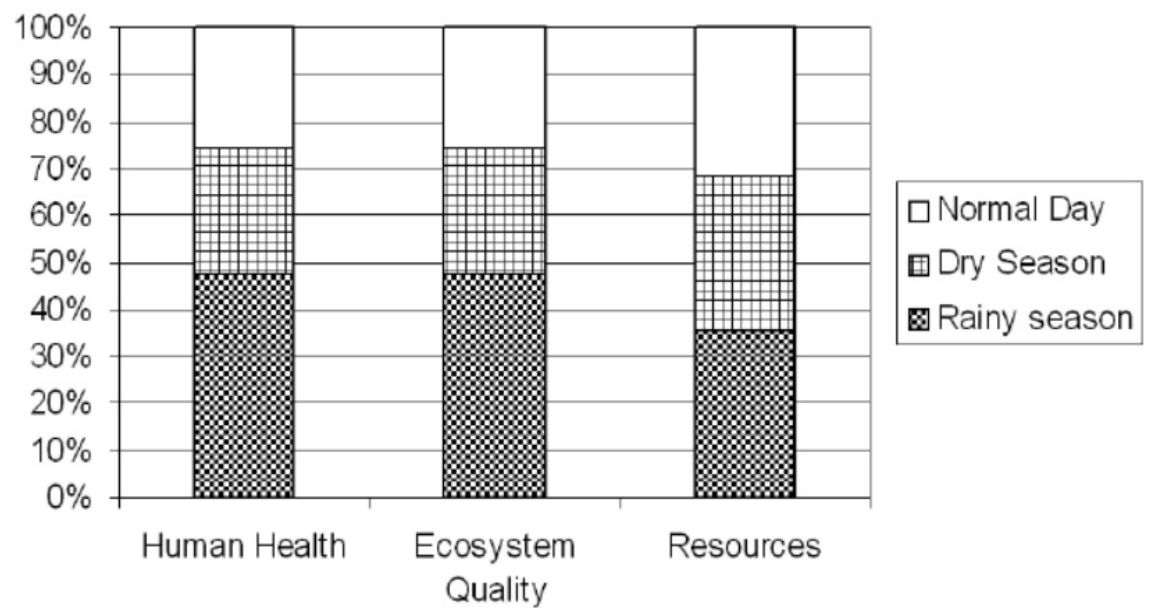

Figure 3. Characterization According to Three Protection Areas

Analysis is focused on three damage categories, namely, damage to human health, damage to ecosystem quality and damage to resource depletion. Analysis found that during the rainy season, the situation has the potential to cause higher damage to human health $(0.0407$ DALY) and ecosystem quality (1.92E3 $\mathrm{PDF}^{*} \mathrm{~m} 2 \mathrm{yr}$ ) at about $46 \%$ each compared to the dry season and a normal day. However, during the dry season, even though the value is much lower than during the rainy season, it is still higher than a normal day, but the difference is not too large (the difference in value of 0.0014 DALY in Human Health damage and 0.07E3 $\mathrm{PDF}^{*} \mathrm{~m} 2 \mathrm{yr}$ in ecosystem quality damage). In damage to resources, the rainy season is still higher compared to the dry season and a normal day, but the contribution does not exceed $40 \%$. Meanwhile, the dry season still contributes higher compared to a normal day. Values for the rainy season, dry season and a normal day are 578, 536 and 521 MJ surplus, respectively. Analysis shows that two main substances contribute to these three damage categories. The substances are polyaluminium chloride (PAC) and natural gas. The PAC chemical production process releases sulphur oxides and nitrogen oxides that contribute to human health and ecosystem quality damage, while electricity generation contributes to natural resources depletion damage. 


\begin{tabular}{|l|l|c|c|c|}
\hline Impact Category & Unit & Rainy Season & Dry Season & Normal Day \\
\hline Carcinogens & DALY & $7.16 \mathrm{E}-06$ & $6.62 \mathrm{E}-06$ & $6.4 \mathrm{E}-06$ \\
\hline Resp. Organics & DALY & $1.17 \mathrm{E}-07$ & $1.06 \mathrm{E}-07$ & $1.01 \mathrm{E}-07$ \\
\hline Resp. Inorganics & DALY & 0.040633 & 0.023199 & 0.02182 \\
\hline Climate Change & DALY & $8.06 \mathrm{E}-05$ & $7.5 \mathrm{E}-05$ & $7.2 \mathrm{E}-05$ \\
\hline Radiation & DALY & $1.71 \mathrm{E}-08$ & $1.85 \mathrm{E}-08$ & $1.17 \mathrm{E}-08$ \\
\hline Ozone Layer & DALY & $4.79 \mathrm{E}-09$ & $4.27 \mathrm{E}-09$ & $4.2 \mathrm{E}-09$ \\
\hline Ecotoxicity & PDF*m2yr & 2.036848 & 1.871666 & 1.851406 \\
\hline $\begin{array}{l}\text { Acidification/Eutrophicati } \\
\text { on }\end{array}$ & PDF*m2yr $^{*}$ & 1915.167 & 1093.544 & 1028.461 \\
\hline Land Use & PDF*m2yr & 0.053107 & 0.057419 & 0.036363 \\
\hline Minerals & MJ Surplus & 0.011961 & 0.01291 & 0.008192 \\
\hline Fossil Fuels & MJ Surplus & 577.824 & 535.6501 & 521.4128 \\
\hline
\end{tabular}

Table 4. Characterization to Impact Category for Different Situations.

From impact analysis (refer Table 4), the rainy season surpassed other categories in all impact categories (carcinogens, respiratory organics, respiratory inorganics, climate change and ozone layer) in human health damage, except for the radiation impact category. For the radiation impact category, the rainy season falls into second place followed by a normal day. In the rest of the categories included in the damage to environmental quality category and natural resources depletion, the highest impact is contributed most by the rainy season (ecotoxicity, acidification/eutrophication, land use, minerals and fossil fuels.

\subsubsection{Normalization}

Normalization expresses the magnitude of the impact scores on a scale which is common to all the categories of impact. Impact scores and resource consumptions from characterization are related to a common reference in order to facilitate comparisons across impact categories (Huijbregts et al., 2003). The impact scores are usually expressed in person equivalents, PE. The PE represents the annual impact from an average person and is useful for bringing together the rather diverse environmental impacts on a common scale. Normalization is an optional element in the ISO 14040 series. The following are the results of the normalization analysis for the impact category obtained (refer Table 5)

Normalization shows the damage to human health quality as the main item. Impact to respiratory inorganic is pointed out as the main cause. The value for this impact category in the rainy season, the dry season and a normal day is 2.65, 1.51 and 6.6E-06 DALY, respectively. Meanwhile in the damage to ecosystem category, acidification/eutrophication is valued at $0.37,0.21$ and 0.20 for the rainy season, the dry season and a normal day, respectively. However, damage to ecosystem quality is in second place after damage to human health. The resource category is last in ranking as the impact contribution is the lowest among all the impact categories. For this damage, the fossil fuels impact category is higher compared to minerals. The contribution value for the rainy season, the dry season 
and a normal day is $0.07,0.063$ and 0.062 , respectively. The rainy season remains the highest contributor for this impact category.

\begin{tabular}{|l|r|r|r|}
\hline Impact Category & \multicolumn{1}{|l|}{ Rainy Season } & \multicolumn{1}{|l|}{ Dry Season } & Normal Day \\
\hline Carcinogens & 0.000466 & 0.000431 & 0.000417 \\
\hline Resp. Organics & $7.64 \mathrm{E}-06$ & $6.92 \mathrm{E}-06$ & $6.6 \mathrm{E}-06$ \\
\hline Resp. Inorganics & 2.64518 & 1.510249 & 1.420503 \\
\hline Climate Change & 0.005246 & 0.004881 & 0.004689 \\
\hline Radiation & $1.11 \mathrm{E}-06$ & $1.2 \mathrm{E}-06$ & $7.61 \mathrm{E}-07$ \\
\hline Ozone Layer & $3.12 \mathrm{E}-07$ & $2.78 \mathrm{E}-07$ & $2.73 \mathrm{E}-07$ \\
\hline Ecotoxicity & 0.000397 & 0.000365 & 0.000361 \\
\hline Acidification/Eutrophication & 0.373457 & 0.213241 & 0.20055 \\
\hline Land Use & $1.04 \mathrm{E}-05$ & $1.12 \mathrm{E}-05$ & $7.09 \mathrm{E}-06$ \\
\hline Minerals & $1.42 \mathrm{E}-06$ & $1.54 \mathrm{E}-06$ & $9.75 \mathrm{E}-07$ \\
\hline Fossil Fuels & 0.068761 & 0.063742 & 0.062048 \\
\hline
\end{tabular}

Table 5. Normalization to Impact Category for Different Situation.

\subsubsection{Weighting}

Weighting is also known as valuation. Weighting is the last step in LCIA where a ranking is undertaken of the different environmental impact categories and resource consumption, reflecting the relative importance they are assigned in the study (Soares et al., 2006; Pennington et al., 2004). The aim of this step is to arrive at a further interpretation and aggregation of the data of the impact assessment. The importance of the impact categories in relation to each other is a value-bound procedure based on an assessment of the relative environmental harm. This assessment will therefore reflect social values and preferences (Consoli et al., 1993). Weighting is another optional element.

Weighting analysis shows a result similar to normalization analysis where the first ranking remains with damage to human health followed by damage to ecosystem quality and damage to resources (refer Figure 4). Values for damage to human health are 795, 455 and $428 \mathrm{Pt}$ for the rainy season, the dry season and a normal day, respectively. Damage to ecosystem quality is at second place with a difference between $340 \mathrm{Pt}$ (rainy season), 369.4Pt (dry season) and $408 \mathrm{Pt}$ (normal day) compared to the damage to human health category. Damage to resources category is in last place, indicating that this category is seen as contributing the least impact compared to damage to human health and ecosystem quality. Values for the three situations are 20.6 Pt (rainy season), 19.1Pt (dry season) and 18.6 Pt (normal day). 


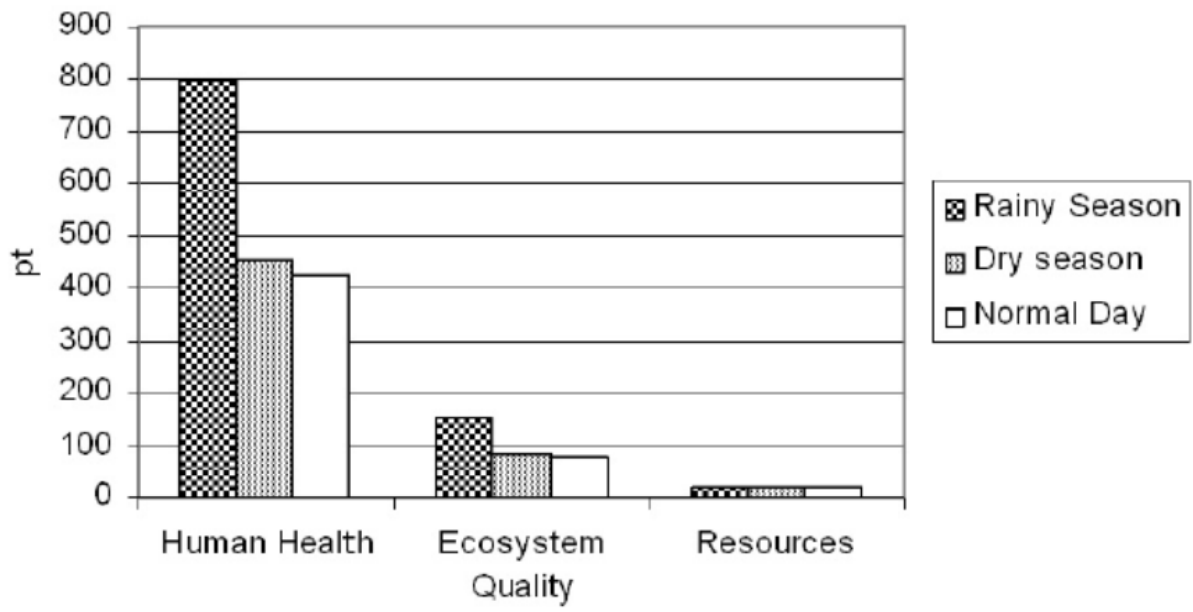

Figure 4. Weighting in Damage Assessment for Three Different Situations.

\subsubsection{Life Cycle Assessment Interpretation (LCAI)}

Interpretation is the phase of the LCA where the results of the other phase are interpreted according to the goal of the study using sensitivity and uncertainty analysis. The outcome of the interpretation may be a conclusion serving as a recommendation to the decision makers, who will normally consider the environmental and resource impacts together with other decision criteria (such as economic and social aspects) (Hauschild et al., 2005).

\subsubsection{Improvement assessment}

From the analysis conducted, There are two weaknesses identified:

1. Production of PAC: contributed to damage to human health quality and damage to ecosystem quality. The process in producing this chemical releases two other dangerous chemicals; nitrogen oxides and sulphur oxides.

2. Depletion of fossil fuel, namely, natural gas: natural gas is used in electricity generation.

These weaknesses could be overcome using more environmentally friendly alternatives such as:

a. Replacing PAC with alum. PAC is a coagulant that could be replaced with other chemical substance such as alum. In this case, the water treatment plant uses both coagulants in similar quantities. Thus, the suggestion is for the complete PAC replacement with alum to depict the impact of the replacement.

b. Natural resource depletion - natural gas: the existing advantages that water treatment plants have must be given attention and complete dependence in natural gas used as fuel for electricity generation is to be avoided. The main advantage is that the constant flow of water in water treatment plants could be used to generate electricity. Other than that, the location of water treatment plants usually exposed to solar radiation is also an 
advantage that should not be taken lightly. The use of solar panels could assist in getting alternative electricity sources from this existing advantage. Thus, a suggestion made to reduce the impact of electricity generation is the use of solar panels $(25 \%)$, hydroelectric generators (25\%) and natural gas (50\%).

Background data for solar panels and hydroelectrics in Simapro 7 software is used to compare the actual results (natural gas usage) with the suggested corrective measure using the combination electricity generation process. The results of the weighting analysis for the corrective suggestions are shown in Figure 5.

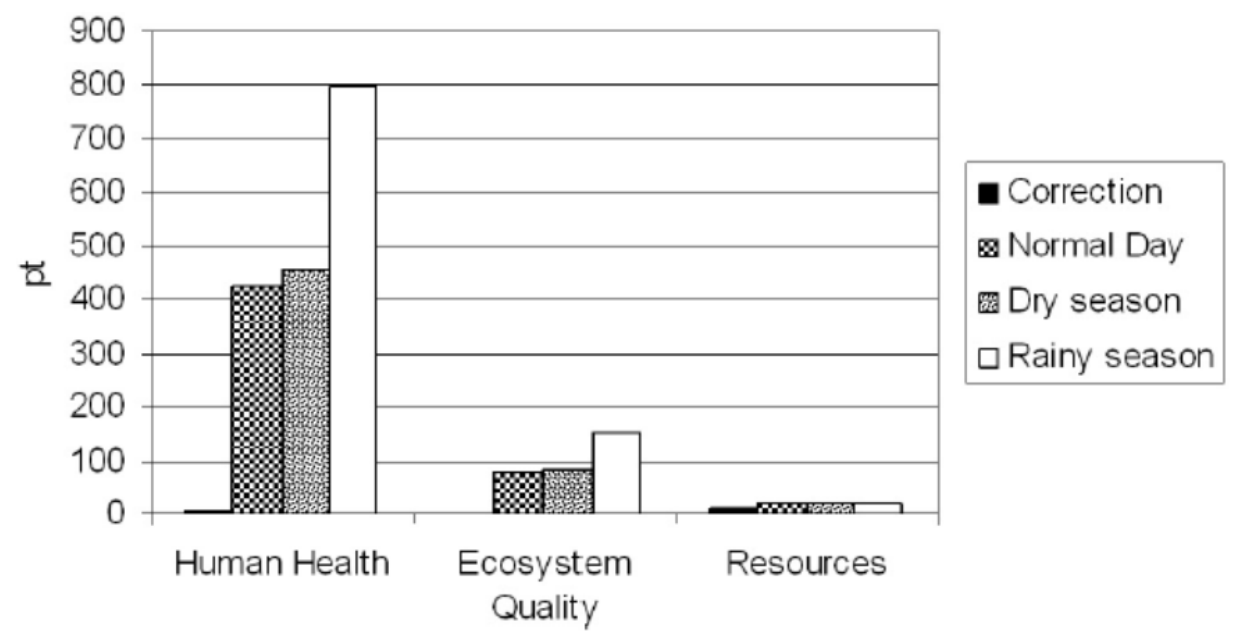

Figure 5. Weighting Analysis with Corrective Measures to Overcome Damage to Human Health, Damage to Ecosystem Quality and Damage to Resources

From the analysis conducted, both damage to human health and ecosystem quality can be reduced by more than $90 \%$. For example, in the damage to human health category, the original value for the rainy season $(795 \mathrm{Pt})$, the dry season $(455 \mathrm{Pt})$ and a normal day $(428 \mathrm{Pt})$ can be reduced to $2.65 \mathrm{Pt}$ in total (the total of each three different situations). This is the same with damage to ecosystem quality, the original value for the rainy season $(150 \mathrm{Pt})$, the dry season $(85.4 \mathrm{Pt})$ and a normal day $(80.4 \mathrm{Pt})$ can be reduced to a mere $0.48 \mathrm{Pt}$ in total (the total of each three different situations). However, the use of hybrid technology in electricity generation can reduce $50 \%$ of the damage to resources. The analysis also found that the use of hybrid technology could also potentially have an impact on human health and ecosystem quality.

\section{Conclusion}

The goal of this study is to analyse the damage that would happen from the use of chemical use and electricity generation based on two extreme climate conditions in Malaysia: the rainy season and the dry season. Both these climate conditions are also linked to world 
climate change which is a hot topic nowadays. Based on the analysis of environment impact using the Ecoindicator 99 evalution method, it is found that the rainy season and the dry season contribute higher to environmental damage, namely, damage to human health, damage to ecosystem quality and damage to resources if compared to normal days. The rainy season is found to contribute much higher impact compared to the dry season and a normal day. The dry season still contributes impact to the environment, but insignificantly compared to normal days. The consumption of alum, PAC and chlorine increases during the rainy season to ensure that treated water fits the standard set. The increase in these chemicals has the potential to cause environmental damage. The chemical that was identified to contribute to this damage is PAC. The production of this chemical releases two hazardous by-product chemicals, namely, nitrogen oxides and sulphur oxides. Nevertheless, the damage could be reduced by completely replacing the coagulant with a more environmentally friendly coagulant such as alum. After the replacement of the chemical, the burden on ecosystem quality and human health could be reduced by up to $80 \%-90 \%$. Damage to natural resources depletion is caused by electricity generation using natural gas. Advantages at the water treatment plants could be fully utilized to avoid dependence on natural gas. This includes the running water in the water treatment system and water treatment plant locations that are exposed to solar radiation which could be harnessed to generate electricity. Hybrid electricity generation could reduce the complete dependence on fossil fuel natural gas in water treatment plants.

Even though the replacement of PAC with the more ecosystem friendly alum could reduce the damage to ecosystem quality and human health quality, the disadvantage of alum use is that it generates a high quantity of sludge. Though there are claims that sludge produced from water treatment plants is not dangerous compared to sludge produced by wastewater treatment plants, it can have negative effects on the environment, especially if this sludge is released directly into rivers, as is still currently practised by some water treatment plants in Malaysia. The proportion - 25\% (solar panels): 25\% (hydroelectric): 50\% (natural gas) suggested to reduce the dependence on natural gas might be improved further, as it is currently only able to reduce it by about $50 \%$. However, if this suggestion is put into action, it would at least reduce the use of fossil fuel natural gas.

World climate change demands sustainable development practices. Without sustainable development in environmental management, damage to the environment is inevitable. Global warming is an example of this caused by anthropogenic activities. The results are disasters, such as frequent droughts and floods, that occur in Malaysia. This situation applies to physical disasters and also indirectly causes environmental damage when river water needs to be treated with higher chemical dosages during the rainy and dry seasons. By using LCA as the environmental assessment tool, environmental damage could be foreseen. Among the potential damage from these two extreme climates are damage to human health (especially respiratory inorganic impact), damage to ecosystem quality (especially acidification/eutrophication impact) and damage to resources (especially impact to fossil fuels). 


\section{Author details}

Amir Hamzah Sharaai

Department of Environmental Management, Faculty of Environmental Studies, Universiti Putra Malaysia, Serdang, Malaysia

Noor Zalina Mahmood and Abdul Halim Sulaiman Institute of Biological Sciences, Faculty of Science, University of Malaya, Kuala Lumpur, Malaysia

\section{References}

Angela, M., No Water Rationing in Klang Valley, in The Sun. 2002: Shah Alam.

Bakar, S.A., M.F. Yusof and W.S. Amly, Johor hampir lumpuh, in Utusan Online. 2007: Johor Baharu.

Bare, J. C. \& Gloria, T. P. (2008). Environmental impact assessment taxonomy providing comprehensive coverage of midpoints, endpoints, damages, and areas of protection. Journal of Cleaner Production(16), 1021-1035.

Bare, J. C., Hofstetter, P., Pennington, D. W. \& Udo de Haes, H. A. (2000). Life Cycle Impact Assessment Workshop Summary. Midpoints versus Endpoints: The Sacrifices and Benefits. The International Journal of Life Cycle Assessment, 5(6), 319 - 326.

Bovea, M. D. \& Gallardo, A. (2006). The influence of impact assessment methods on materials selection for eco-design. Materials and Design, 27, 209-215.

BBC News, Malaysia floods test aid efforts, http://www.bbc.com/news/ in BBC News. 2007.

Bernama, Residents Advised To Be Cautious Of Inter-Monsoon Period, in Bernama. 2008: Kuala Lumpur.

Bovea, M.D. and A. Gallardo, 2006. The influence of impact assessment methods on materials selection for eco-design. Materials and Design, 27: 209-215.

Climate Ark. Malaysian state begins water rationing amid dry spell 2002 [cited 23 July 2008]; Available from: http://www.climateark.org/.

Clarke, J. (1998). Concrete Reinforced with Fibre Reinforced Plastic. Materials World, 6(2), 7880.

Consoli, F., et al., 1993. Guideline for life cycle assessment: A code of practice. Society of Environmental Toxicology and Chemistry workshop report: Sesimbra, Portugal.

Dreyer, L. C., Niemann, A. L. \& Hauschild, M. Z. (2003). Comparison of three different LCIA methods: EDIP97, CML2001 and Eco-indicator 99. Does it matter which one you choose? The International Journal of Life Cycle Assessment, 8(4), 191-200.

Goedkoop, M., Schryver, A. N. \& Oele, M. (2007). Introduction to LCA with Simapro 7. Amersfoort: PRé Consultants.

Goedkoop, M. and R. Spriensma, 2001. The Eco-indicator 99 - A damage oriented method for Life Cycle Assessment Methodology Report. 3rd ed. BB Amersfoort: Pre Consultants. 132.

Guinée, J. B. (2002). Handbook on Life Cycle Assessment: Operational Guide to the ISO Standards: Springer, Netherlands

Hauschild, M., Why LCA? 2007, Department of Manufacturing Engineering and Management, Technical University of Denmark. 
Huijbregts, M.A.J., et al., 2003. Normalisation figures for environmental life-cycle assessment The

Netherlands (1997/1998), Western Europe (1995) and the world (1990 and 1995). Journal of Cleaner Production, 11: 737-748.

Heijungs, R., Goedkoop, M., Struijs, J., Effting, S., Sevenster, M. \& Huppes, G. (2003). Towards a life cycle impact assessment method which comprises category indicators at the midpoint and the endpoint level. Report of the first project phase Design of the new method [Electronic Version]. Retrieved 7 Mac 2007, from http://www.leidenuniv.nl/cml/ssp/publications/recipe_phase1.pdf

Hauschild, M., J. Jeswiet and L. Alting, 2005. From Life Cycle Assessment to Sustainable Production: Status and Perspective. Annals of the CIRP, 54/2/2005: 535-555.

ISO14000, Malaysian standards handbook on environmental management: MS ISO 14000 Series $2^{\text {nd }}$ Ed. 2000, Shah Alam, Malaysia: SIRIM.

Jolliet, O., Brent, A., Goedkoop, M., Itsubo, N., Mueller-Wenk, R., Peña, C., et al. (2003). Life Cycle Impact Assessment Programme of the Life Cycle Initiative. Final report of the LCIA Definition study [Electronic Version]. Retrieved 17 September 2007, from http://lcinitiative.unep.fr/includes/file.asp?site=lcinit\&file=F7BF1ABF-8B98-4A95-9FDE3E32EB7C4EC4

Jolliet, O., Margni, M., Charles, R., Humbert, S., Payet, J., Rebitzer, G., et al. (2003). IMPACT 2002+: A New Life Cycle Impact Assessment Methodology. The International Journal of Life Cycle Assessment, 8(6), 324-330.

Jolliet, O., Müller-Wenk, R., Bare, J., Brent, A., Goedkoop, M., Heijungs, R., et al. (2004). The LCIA midpoint-damage framework of the UNEP/SETAC life cycle initiative. The International Journal of Life Cycle Assessment, 9(6), 394-404.

Khan, F.I., V. Raveender and T. Husain, 2002. Effective Environmental Management Through Life Cycle Assessment. Journal of Loss Prevention in the Process Industries, 15: 455-466.

Mangena, S. J. \& Brent, A. C. (2006). Application of a Life Cycle Impact Assessment framework to evaluate and compare environmental performances with economic values of supplied coal products. Journal of Cleaner Production(14), 1071-1084.

Miettinen, P. \& Hamalainen, R. P. (1997). How to benefit from decision analysis in environmental life cycle assessment (LCA). European Journal of Operational Research, 102, 279-294.

Minister of Science Technology, 2000. and the Environment Malaysia, Malaysia Initial National Communication (INC). Minister of Science Technology and the Environment Malaysia: Putra Jaya,. p. 131.

Moberg, Á., Finnveden, G., Johansson, J. \& Lind, P. (2005). Life cycle assessment of energy from solid waste-part 2: landfilling compared to other treatment methods. Journal of Cleaner Production, 13, 231-240.

Ntiamoah, A. \& Afrane, G. (2008). Environmental impacts of cocoa production and processing in Ghana: life cycle assessment approach. Journal of Cleaner Production, 16, 1735-1740. 
Pennington, D. W., Potting, J., Finnveden, G., Lindeijer, E., Jolliet, O., Rydberg, T., et al. (2004). Life cycle assessment part 2: Current impact assessment practice. Environment International, 30, 721-739.

Rahman, H.A. A survey on a river pollution in Malaysia in Geographic Conference 2007. 2007. UPSI

Sastry, C. A. (1996). Water Treatment Plants. New Delhi: Narosa Publishing House.

Sleeswijk, A. W., van Oersc, L. F. C. M., Guinée, J. B., Struijsd, J. \& Huijbregtsb, M. A. J. (2008).

Normalisation in product life cycle assessment: An LCA of the global and European economic systems in the year 2000. Science of the Total Environment, 390, 227-240.

Soares, S. R., Toffoletto, L. \& Deschenes, L. (2006). Development of weighting factors in the context of LCIA. Journal of Cleaner Production, 14 649-660.

Typhoon Utor to Blame, in The Star. 2006: Cyber Jaya. 